\title{
DESCRIPTIONS OF FIVE NEW SPECIES OF GORYPHUS HOLMGREN (HYMENOPTERA: ICHNEUMONIDAE) FROM SOUTHERN INDIA
}

\author{
K. Sudheer ${ }^{1}$ and T.C. Narendran ${ }^{2}$ \\ 1,2 Systematic Entomology Laboratory, Department of Zoology, University of Calicut, Kerala 673635, India \\ Email: ${ }^{2}$ sudheer_kt03@yahoo.co.in; ${ }^{2}$ drtcnarendran@yahoo.com
}

\begin{abstract}
Five new species of Goryphus Holmgren viz., Goryphus konishii sp. nov., Goryphus nilamburensis sp. nov., Goryphus rexus sp. nov., Goryphus townesi $s p$. nov. and Goryphus sringeriensis $s p$. nov. are described from southern India. G. konishii sp. nov. can be distinguished from the closely related G. brahminus (Cameron) in having smaller malar space and prepectal carina, metapleurum distinctly rugose and colour of the face and abdominal tergites. G. nilamburensis sp. nov. is similar to G. nigricoxatus Betrem in many features but differs from the latter in the sculpture of face, frons, propodeum and pronotum. G. rexus sp. nov. can be distinguished from the closely resembling $\mathrm{G}$. tuberculatus Uchida and G. tirkyi Jonathan and Gupta in having a distinct notauli extending to apex of mesoscutum. G. sringeriensis sp. nov. can be identified from related species $\mathrm{G}$. apollonis Jonathan and Gupta and G. rangaparensis Jonathan and Gupta in the mesoscutum being distinctly rugoso-punctate, rugosities weaker in the middle of each lobe. G. townesi $s p$. nov. differs from the closely resembling $\mathrm{G}$. inferus (Szepligeti) and $\mathrm{G}$. cameroni Betrem in having a larger malar space and the colour of face and abdominal tergites.
\end{abstract}

\section{KEYWordS}

Goryphus konishii sp. nov., Goryphus nilamburensis $s p$. nov., Goryphus rexus sp. nov., Goryphus sringeriensis $s p$. nov., Goryphus townesi sp. nov., Hymenoptera, Ichneumonidae, India, Karnataka, Kerala, new descriptions

\section{AbBreviations}

DZUC - Department of Zoology, University of Calicut; F Female; FWL - Fore wing length; FWW - Fore wing width; HW - Head width; HL - Head length; HWL - Hind wing length; HWW - Hind wing width; M - Male; ZSIK - Western Ghats Regional Station of the Zoological Survey of India, Kozhikode.

Ichneumonidae is the largest family of the Order Hymenoptera, with approximately 60,000 species (Townes, 1969; Yu, 2002). Currently 39 subfamilies are recognized in the family (Yu, 2002), of which the largest subfamily is Cryptinae. The genus Goryphus Holmgren belongs to the tribe Cryptini of this subfamily (Wahl, 1999). Holmgren (1868) erected the genus Goryphus with G. basilaris as its type species. The genus is very large and widely distributed in the Oriental, Australian and Ethiopian Regions. Only two species, G. basilaris and $G$. nursei occurs in northern China (eastern Palaearctic). The relevant citings to the taxonomy of Oriental species of Goryphus includes that of Tosquinet (1903), Cameron (1904; 1905), Ashmead (1905), Betrem (1941), Jonathan and Gupta (1973), and many others. Gupta (1987) reported 73 species from IndoAustralian region, of which 29 species were from India. Two species were later described by Sathe et al. (1997). In this paper, five new species, viz., Goryphus konishii sp. nov., G. nilamburensis sp. nov., G. rexus sp. nov., G. sringeriensis sp.

nov. and G. townesi sp. nov. are described from the southern Indian states of Kerala and Karnataka. Most of the species of Goryphus were collected from dense bushes. Goryphus konishii sp. nov., and G. nilamburensis sp. nov., were collected from dense forests, while G. rexus sp. nov., was collected from coconut plantation. The type materials of these taxa are deposited in the Collections of the Systematic Entomology Laboratory, Department of Zoology, University of Calicut (DZUC) for the time being but eventually will be transferred to the Western Ghats Regional Station of the Zoological Survey of India, Kozhikode, Kerala (ZSIK).

\section{Goryphus konishii sp. nov.} (Figs. 1-5)

\section{Material Examined}

Holotype: Female, 30.i.2003, Ganapathikallu ( $\left.75^{0} 15^{\prime} \mathrm{E}-11^{0} 18^{\prime} \mathrm{N}\right)$, Nilambur forests, Kerala, coll. T. Divakaran (Reg. No. SK 350). Paratypes: Female, 30.i.2003, Ganapathikallu, $\left(75^{0} 15^{\prime} \mathrm{E}-11^{0} 18^{\prime} \mathrm{N}\right)$, Nilambur forests, Kerala, coll. K. Sudheer (Reg. No. SK 351); Female, 30.i.2003, Ganapathikallu, $\left(75^{\circ} 15^{\prime} \mathrm{E}-11^{0} 18^{\prime} \mathrm{N}\right)$, Nilambur forests, Kerala, coll. P. Girish Kumar (Reg. No. SK 352).

\section{Etymology}

Named after Dr. K. Konishi, Hokkaido University, Japan for his valuable contributions to the systematics of Ichneumonidae.

\section{Diagnosis}

Female: Length - 9.6mm (excluding ovipositor). Body covered with fine, short hairs.

Head: In dorsal view HW - 2mm and HL - 0.5mm (Fig. 3); in front view $\mathrm{HW}-2 \mathrm{~mm}$ and $\mathrm{HL}-1.5 \mathrm{~mm}$ (Fig. 2); face strongly and closely punctate, tending to be wrinkled, at sides tending to be smooth; clypeus with distinct punctures, interstices smooth, distance between punctures more than diameter of punctures, apical margin impressed and smooth; malar space granulose, $0.3 \mathrm{x}$ basal width of mandible; mandibles punctate, smooth towards apex, teeth subequal; frons below median ocellus rugose, median longitudinal carina present, tending to be smooth at sides; vertex and temple with minute, close punctures; interocellar distance $0.57 \mathrm{x}$ ocellocular distance, $1.33 \mathrm{x}$ distance between median and lateral ocelli; antenna (Fig. 1) with 28 segments; scape $1.1 \mathrm{x}$ as long as its width, $1.43 \mathrm{x}$ as long as pedicel; pedicel $1.4 \mathrm{x}$ as long as its width, $0.21 \mathrm{x}$ as long as length of first flagellar segment; first flagellar segment $1.03 \mathrm{x}$ as long as second flagellar segment, 1.18x as long as third flagellar segment, 6.6x as long as its width at apex. 


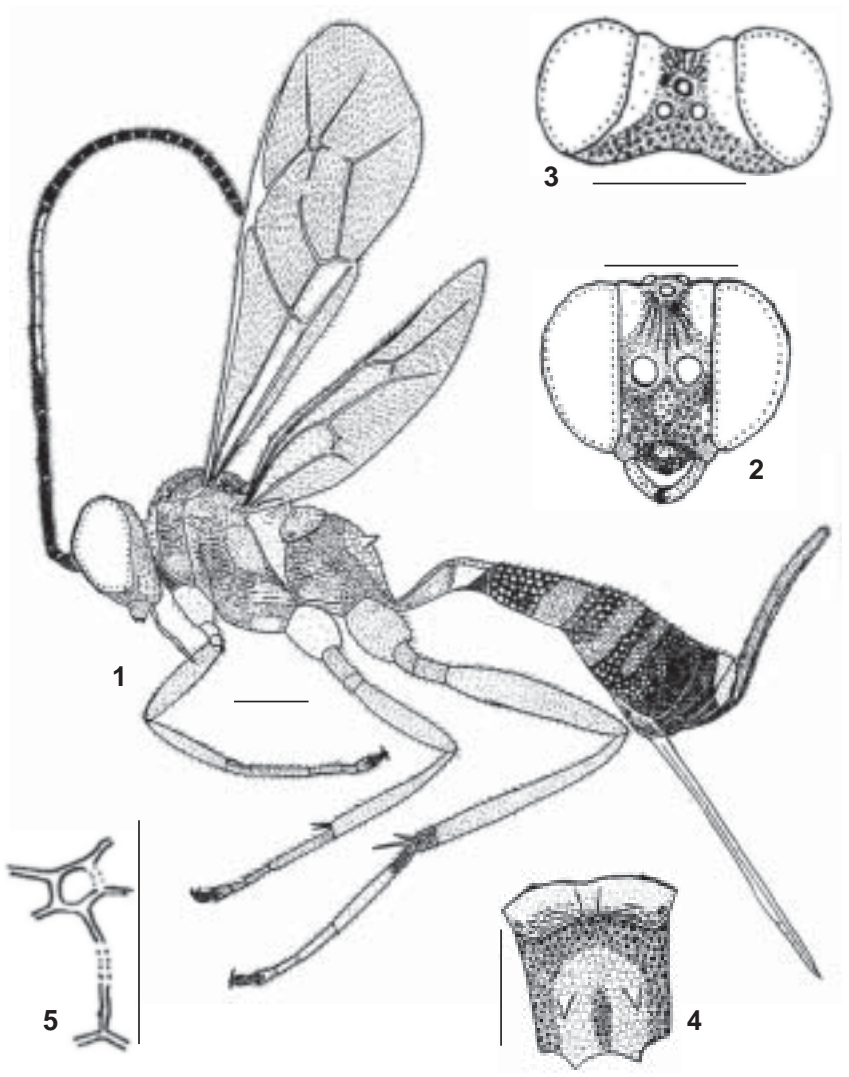

Figures 1-5. Goryphus konishii sp. nov. Female 1 - Body profile; 2 - Head-Front view; 3 - Head-Dorsal view; 4 - Propodeum; 5 - Areolet. Scale $=1 \mathrm{~mm}$

Thorax: $2.82 \mathrm{x}$ as long as width between tegulae, $5.17 \mathrm{x}$ as long as head length in dorsal view; pronotum with 3-4 coarse striations in middle, with shallow punctures above, pronotal collar with minute, close punctures; epomia strong, complete, reaching upper margin and turning mesad; mesoscutum with fine, close punctures, punctures running into straitions, aciculate along margin of lobes; scutellum with fine, shallow punctures; lateral carina of scutellum extending its full length; metascutellum smooth; mesopleurum coarsely rugose, speculum mat; prepectal carina extending about $0.75 \mathrm{x}$ height of mesopleurum; metapleurum rugose, juxtacoxal carina present; propodeum (Fig. 4) basad of basal carina rough and wrinkled, basal carina complete, slightly curved in middle, basal stumps of longitudinal carina present, area between basal carina and apex reticulate, apical carina represented by crest-like apophyses, absent in middle; spiracle oval, small; FWL - 6.78mm; HWL 4.83mm; FWW - 1.6mm; HWW - 1.1mm; areolet (Fig. 5) pentagonal, 6x as high as width of bordering veins, intercubitii parallel, second intercubitus faint; nervulus slightly basad of basal vein; nervellus intercepted below middle; hind wing with one basal and eight apical hamuli.

Abdomen: Length of first tergite $1.7 \mathrm{x}$ width at apex, $1.0 \mathrm{x}$ length of second tergite; first tergite largely smooth, with fine, close punctures towards apex; second and third tergites with close, coarse punctures; fourth tergite shallowly punctate; fifth and remaining tergites subpolished; ovipositor tip long, teeth on lower valve moderately strong; length of ovipositor $-4.1 \mathrm{~mm}$.

Colour: Black except following markings: face in middle, orbital stripes of face, base of clypeus, orbital stripes of frons, a small mark on lower temple near mandibular base, pronotal collar, upper margin of pronotum, subtegular ridge, apex of middle lobe of mesoscutum, scutellum, metascutellum, hind margin of metanotum, two marks on mesopleurum one above and one below sternaulus near base of mid coxa, mark on metapleurum, an inverted horse-shoe shaped mark on propodeum, apical bands on first to third abdominal tergites, fourth, seventh and eighth tergites in middle apically, fore and mid coxae, fore trochanters, apical part of first hind tarsal segment, second to fourth hind tarsal segments yellow; flagellar segments apical third to basal part of ninth white above, rest dark brown; basal part of first tergite, trochanters except fore trochanters, femora of all legs and all tibiae except apex of hind tibia orange; tegula, last tarsal segments, arolium and claws of all legs, ovipositor and ovipositor sheath, apex of hind tibia, mandibles at apex and wing veins dark brown; wings clear hyaline.

Male: Unknown.

Host: Unknown.

Biology: Unknown.

\section{Discussion}

Goryphus konishii sp. nov. closely resembles G. brahminus (Cameron) in having an inverted horse-shoe shaped mark on propodeum and similar sculpture on frons and propodeum. However G. konishii sp. nov. differs from G. brahminus (Cameron) in the following characteristics: (i) Malar space granulose, $0.3 x$ basal width of mandible in $G$. konishii sp. nov. (In G. brahminus malar space rugose, about $0.4 \mathrm{x}$ basal width of mandible); (ii) Metapleurum distinctly rugose in G. konishii sp. nov. (In G. brahminus metapleurum largely smooth); (iii) Fifth and sixth abdominal tergites completely black in G. konishii sp. nov. (In G. brahminus all abdominal tergites with apical yellow bands, except fifth and sixth tergites with medially interrupted bands); (iv) Face and speculum black except face in middle yellow in G. konishii sp. nov. (Face and clypeus jointly except apical margin of clypeus and speculum yellow in G. brahminus); and (v) Prepectal carina extending about $0.75 \mathrm{x}$ height of mesopleurum in G. konishii sp. nov. (In G. brahminus prepectal carina extending to full height of mesopleurum).

\section{Goryphus nilamburensis sp. nov.} (Figs. 6-10)

\section{Material examined}

Holotype: Female, 30.i.2003, Ganapathikallu $\left(76^{0} 15^{\prime} \mathrm{E}-11^{0} 18^{\prime} \mathrm{N}\right)$, Nilambur forests, Kerala, coll. P. Girishkumar (Reg. No. SK 353).

\section{Etymology}

Named after the collection locality. 


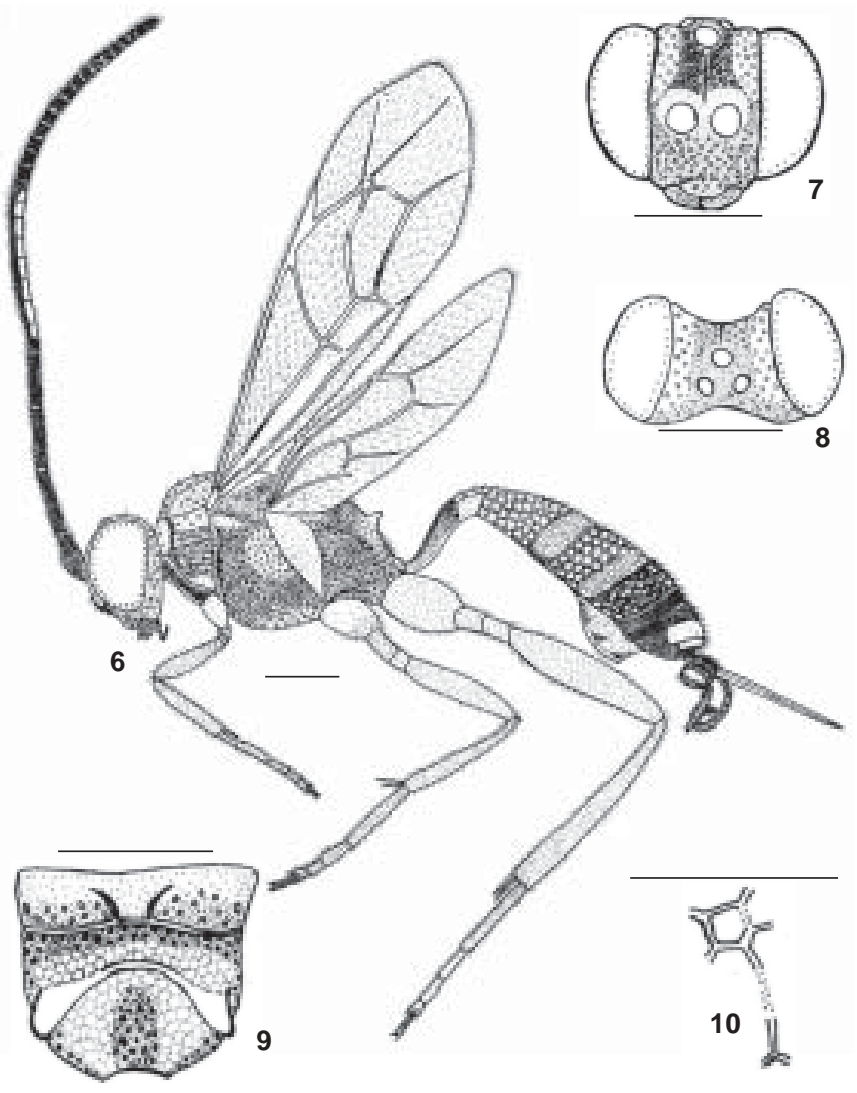

Figures 6-10. Goryphus nilamburensis sp. nov. Female 6 - Body profile; 7 - Head-Front view; 8 - Head-Dorsal view; 9 - Propodeum; 10 - Areolet. Scale $=1 \mathrm{~mm}$

\section{Diagnosis}

Female: Length - 8.83mm (excluding ovipositor). Body covered with fine, short hairs; hairs longer on propodeum.

Head: In dorsal view HW - 1.94mm and HL - 0.69mm (Fig. 8); in front view HW - 1.94mm and HL - 1.42mm (Fig. 7); face with fine, close punctures, punctures separated by distance of diameter; clypeus with minute, scattered punctures, apical margin impressed; malar space granulose, $0.625 \mathrm{x}$ basal width of mandible (Fig. 6); frons punctate (Fig. 7), interstices smooth, median longitudinal carina extending from median ocellus to middle of antennal sockets; mandibles with minute, sparse punctures, apex smooth; mandibular teeth unequal; interocellar distance $0.5 \mathrm{x}$ ocellocular distance, $1.33 \mathrm{x}$ distance between median and lateral ocelli; vertex with fine, close punctures, appearing to be smooth in lower magnifications; antenna (Fig. 6 ) with 30 segments; scape $0.47 \mathrm{x}$ as long as pedicel, $1.5 \mathrm{x}$ as long as wide; pedicel $0.375 \mathrm{x}$ as long as first flagellar segment; first flagellar segment $8 \mathrm{x}$ as long as wide, 1.07x as long as second flagellar segment; second flagellar segment $7.5 \mathrm{x}$ as long as wide, $1.15 \mathrm{x}$ as long as third flagellar segment.

Thorax: $4.3 \mathrm{x}$ as long as head length in dorsal view, $2.13 \mathrm{x}$ as long as width between tegulae; pronotum distinctly rugose (Fig. 6), upper margin with shallow, sparse punctures, pronotal collar largely smooth, with sparse, minute punctures; epomia strong, reaching to upper margin and turning mesad; mesoscutum with minute, evenly distributed punctures, interstices smooth, punctures separated by distance equal to diameter of punctures; notauli distinct, reaching beyond middle of mesoscutum; scutellum and metascutellum, with shallow, sparse punctures; lateral carina of scutellum confined to its base; mesopleurum strongly reticulate, speculum with minute, evenly scattered punctures, area below sternaulus largely smooth with sparse, scattered, minute punctures; prepectal carina extending full height of mesopleurum; metapleurum reticulate, juxtacoxal carina present; propodeum (Fig. 9) basad of basal carina punctate, basal stumps of longitudinal carina present, area between basal carina and apex strongly reticulate, apical carina complete, strongly arched in middle, crest-like apophyses; FWL - 6.56mm; FWW - 2.05mm; HWL - 4.67mm; HWW - 1.17mm; areolet (Fig. 10) pentagonal, $5 \mathrm{x}$ as high as width of bordering veins, intercubitti parallel, second intercubitus faint; nervulus opposite basal vein (Fig. 6); nervellus intercepted below middle; brachiella extending only less than $0.25 x$ distance to wing margin; hind wing with one basal and eight apical hamuli.

Abdomen: First tergite $1.86 \mathrm{x}$ as long as wide at apex, $1.04 \mathrm{x}$ as long as second tergite; first tergite smooth and shiny, evenly distributed shallow punctures at apex; second and third tergites closely and fourth shallowly punctate; fifth and remaining tergites subpolished; length of ovipositor $-2.39 \mathrm{~mm}$; ovipositor slightly compressed, pointed tip, lower valve with very weak teeth.

Colour: Black except following markings: Palpi, orbital stripes on face and frons, pronotal collar, upper margin of pronotum, tegula, subtegular ridge, apex of middle lobe of mesoscutum, scutellum, metascutellum, hind margin of metanotum, an inverted horse-shoe shaped mark on propodeum, apical band on first to third tergites, seventh and eighth tergite in middle, a small mark on lower pronotum above fore coxa, fore coxa and base of mid coxa and second to fourth tarsal segment of hind leg yellow; fourth to eleventh flagellar segments white dorsally, rest dark brown; legs except fore and mid coxa, and second to fourth tarsal segments of hind leg orange; last tarsal segments and claws of all legs, wing veins and ovipositor sheath dark brown; ovipositor dark red; wings clear hyaline.

Male: Unknown.

Host: Unknown.

\section{Discussion}

G. nilamburensis sp. nov. closely resembles G. nigricoxatus Betrem in having an inverted horse-shoe shaped mark on propodeum, lateral carina of scutellum yellow, face punctate, frons without rugosities and mesoscutum without striations. G. nilamburensis sp. nov. differs from G. nigricoxatus Betrem in the following features: (i) Propodeum basad of basal carina punctate, area between basal carina and apex strongly reticulate in G. nilamburensis sp. nov. (In G. nigricoxatus propodeum basad of basal carina reticulate, rest of propodeum somewhat striated); (ii) Pronotum distinctly rugose, upper margin with 
shallow sparse punctures, pronotal collar largely smooth with sparse minute punctures in G. nilamburensis sp. nov. (In $G$. nigricoxatus pronotum largely smooth, striated below, hind margin indistinctly striate); (iii) Frons punctate in $G$. nilamburensis sp. nov. (In G. nigricoxatus frons smooth and shiny); (iv) In G. nilamburensis sp. nov. face with distinct punctures, punctures separated by distance of diameter (In $G$. nigricoxatus face densely and coarsely punctate); (v) Face except orbital stripes and clypeus black in G. nilamburensis sp. nov. (In G. nigricoxatus face and clypeus yellow); and (vi) Fourth to eleventh flagellar segments white above in $G$. nilamburensis sp. nov. (Eleventh to seventeenth flagellar segments white above in $G$. nigricoxatus).

\section{Goryphus rexus sp. nov.}

(Figs. 11-15)

\section{Material examined}

Holotype: Female, 17.iv.2004, Kumarakom Regional Agricultural Research Station (76026'E-9030'N), Kottayam, Kerala, coll. K. Sudheer (Reg. No. SK 379).

\section{Etymology}

The species name is an arbitrary combination of letters.

\section{Diagnosis}

Female: Body length (excluding ovipositor) - 9.19mm. Body with fine, short, evenly distributed hairs; hairs longer on propodeum.

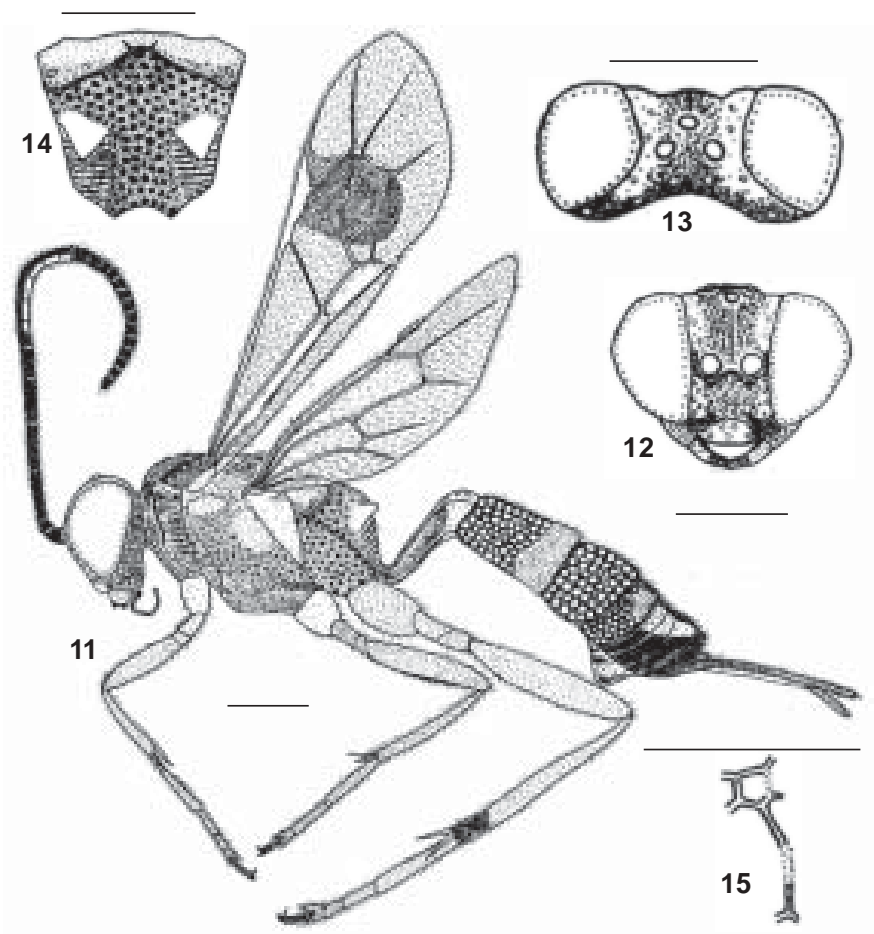

Figures 11-15. Goryphus rexus sp. nov. Female

11 - Body profile; 12 - Head-Front view; 13 - Head-Dorsal view; 14 - Propodeum; $15-$ Areolet. Scale $=1 \mathrm{~mm}$
Head: In dorsal view (Fig. 13) HL - 1.5mm and HW - 2.3mm; HL - $0.72 \mathrm{~mm}$ and HW - 2.3mm in front view (Fig. 12); face closely punctate in middle, at sides punctures scattered, interstices smooth; clypeus largely smooth with a few scattered punctures, apex impressed; malar space granulose, $0.6 \mathrm{x}$ basal width of mandible; mandibles striato-punctate, apex smooth, teeth subequal; frons rugose, with a median longitudinal carina extending from median ocellus to middle of antennal sockets, at sides largely smooth with scattered, fine punctures; interocellar distance $0.5 \mathrm{x}$ ocellocular distance, $2.0 \mathrm{x}$ distance between median and lateral ocelli; vertex and temple largely smooth and shiny, with fine, scattered punctures; antenna (Fig. 11) with 27 segments; scape $1.5 \mathrm{x}$ as long as its width, $2.0 \mathrm{x}$ as long as pedicel; pedicel $0.27 \mathrm{x}$ as long as first flagellar segment; first flagellar segment 5.5x as long as its width at apex, 1.0x as long as second flagellar segment; second flagellar segment $1.05 \mathrm{x}$ as long as third flagellar segment.

Thorax: $2.13 \mathrm{x}$ as long as width between tegulae, $4.38 \mathrm{x}$ as long as head length in dorsal view; pronotum with strongly swollen upper margin, largely trans-striate, upper margin largely smooth with few fine punctures; epomia long and strong, reaching upper margin and turning mesad; mesoscutum distinctly punctate, punctures separated by a distance more than its diameter; notauli distinct, reaching upto apex of mesoscutum, notaular grooves with strong rugosities; scutellum and metascutellum largely smooth and shiny, with shallow punctures; lateral carina of scutellum confined to base; mesopleurum reticulate except speculum and subtegular ridge smooth and shiny, area above and below sternaulus distinctly punctate; prepectal carina extending $0.8 \mathrm{x}$ height of mesopleurum; metapleurum reticulate; propodeum (Fig. 14) reticulate, trans-striate below apophyses, area basad of basal carina punctate, extreme base smooth, basal carina complete, basal stumps of longitudinal carinae present, apical carina represented by tubercle-like apophyses; spiracle oval, connected to basal carina by a small carina; FWL $-6.27 \mathrm{~mm}$; FWW - 2.0mm; HWL - 4.6mm; HWW - 1.2mm; areolet (Fig. 15) pentagonal, $4 \mathrm{x}$ as high as width of bordering veins; nervulus opposite basal vein; nervellus intercepted below middle; hind wing with one basal and six apical hamuli.

Abdomen: First tergite 1.7x as long as its width at apex, 1.08x as long as length of second tergite; first tergite largely smooth, with few scattered punctures; second and third tergites with distinct close punctures (Fig. 11); fourth and remaining tergites with shallow punctures; length of ovipositor $-2.28 \mathrm{~mm}$; lower valve of ovipositor with series of teeth.

Colour: Black except following markings: apical fifth to tenth flagellar segments white above; face with a trilobate mark, clypeus, basal half of mandibles, maxillary palpi, temple near base of mandible, orbital stripes of frons upto level of vertex, pronotal collar, upper margin of pronotum, tegula, subtegular ridge, scutellum, metascutellum, hind margin of metanotum, elongate triangular lateral marks on propodeum including apophyses, apical bands on first and second abdominal tergites and fourth to seventh abdominal tergites with medially interrupted apical bands yellow; legs largely orange except fore 
and mid coxae and fore trochanters yellow, apical 0.25 of hind tibia, fifth hind tarsal segment dark brown; wing veins brown except base of wings yellow; fore wing with a fuscous mark in middle beneath stigma; mandibular teeth and ovipositor deep red and ovipositor sheath dark brown.

Male: Unknown.

Host: Unknown.

Biology: Unknown.

\section{Discussion}

G. rexus sp. nov. closely resembles G. tuberculatus Uchida in having (i) fuscous mark beneath stigma of fore wing, (ii) first abdominal tergite black with apical yellow band, (iii) strongly swollen upper margin of pronotum, (iv) first abdominal tergite longer than second tergite, and (v) base of hind wing yellow. However $G$. rexus sp. nov. can be distinguished from $G$. tuberculatus Uchida in the following characteristics: (i) Face ditinctly punctate in G. rexus sp. nov. (In G. tuberculatus face ruguloso-punctate); (ii) Frons rugose, at sides largely smooth with fine scattered punctures in $G$. rexus sp. nov. (In $G$. tuberculatus frons ruguloso-punctate); (iii) Notauli distinct, extending to apex of mesoscutum in G. rexus sp. nov. (In $G$. tuberculatus notauli distinctly marked in front); and (iv) In $G$. rexus sp. nov. first and second abdominal tergites with complete and fourth to seventh with medially interrupted apical yellow bands (In G. tuberculatus first to fifth, seventh and eighth segments with complete yellow apical bands).

G. rexus sp. nov. is also similar to G. tirkyi Jonathan and Gupta in having (i) lateral carina of scutellum, base of first abdominal tergite and third abdominal tergite completely black, (ii) mesoscutum strongly punctate, (iii) fourth to seventh abdominal tergites with medially interrupted yellow apical bands, and (iv) frons not smooth and shiny. However G. rexus sp. nov. differs from G. tirkyi Jonathan and Gupta in the following features: (i) In $G$. rexus sp. nov. fore wing with fuscous mark beneath stigma (In G. tirkyi fore wing clear hyaline); (ii) In G. rexus sp. nov. malar space $0.67 x$ basal width of mandible (In G. tirkyi malar space $0.8 \mathrm{x}$ basal width of mandible); (iii) Notauli reaching up to apex of mesoscutum in G. rexus sp. nov. (In G. tirkyi notauli reaching beyond middle of mesoscutum, not extending up to apex of mesoscutum); and (iv) In G. rexus sp. nov. areolet 4x as high as width of bordering veins (In G. tirkyi areolet 3x as high as width of bordering veins).

Goryphus sringeriensis sp. nov. (Figs. 16-20)

\section{Material examined}

Holotype: Female, 22.v.2003, Kotta, Sringeri $\left(75^{0} 15^{\prime} \mathrm{E}-13^{0} 25^{\prime} \mathrm{N}\right)$, Karnataka, coll. P.A. Sinu (Reg. No. SK 361).

\section{Etymology}

Named after the collection locality.

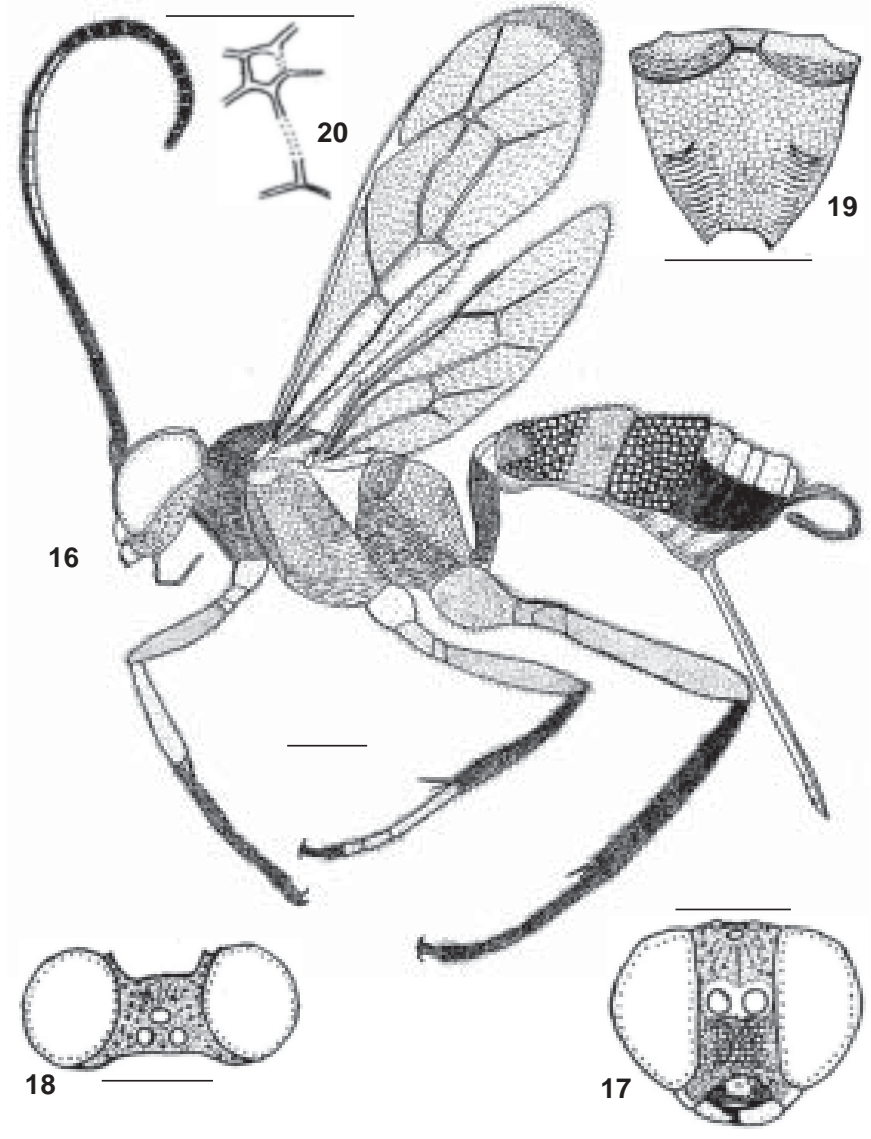

Figures 16-20. Goryphus sringeriensis sp. nov. Female
16 - Body profile; $17-$ Head-Front view; $18-$ Head-Dorsal
view; 19 - Propodeum; 20 - Areolet. Scale $=1 \mathrm{~mm}$

\section{Diagnosis}

Female: Length (excluding ovipositor) - 9.4mm; Body covered with fine, short, white hairs.

Head: In dorsal view (Fig. 18) HL - 0.69mm and HW - 1.16mm; $\mathrm{HL}-1.5 \mathrm{~mm}$ and $\mathrm{HW}-1.16 \mathrm{~mm}$ in front view (Fig. 17); face strongly rugoso-punctate; clypeus with distinct, evenly distributed punctures, interstices smooth and shiny; malar space granulose, $0.4 \mathrm{x}$ basal width of mandible; mandibles punctate, apex smooth and shiny; mandibular teeth subequal; frons largely smooth with fine, scattered punctures, area below median ocellus weakly rugose, median carina weak; vertex and temple largely smooth and shiny, with evenly distributed, fine punctures; lower part of temple with strong wrinkles; antenna (Fig. 16) with 28 segments; scape $1.75 \mathrm{x}$ as long as its width, $2.3 \mathrm{x}$ as long as pedicel; pedicel $0.19 \mathrm{x}$ as long as first flagellar segment; first flagellar segment $8 \mathrm{x}$ as long as its width, 1.03x as long as second flagellar segment, $4 \mathrm{x}$ as long as last flagellar segment; second flagellar segment $1.24 \mathrm{x}$ as long as third flagellar segment.

Thorax: $4.8 \mathrm{x}$ as long as head length in dorsal view, $2.75 \mathrm{x}$ as long as width between tegulae; pronotum strongly swollen, strongly trans-rugose, upper margin with longitudinal rugosities; epomia strong, reaching to upper margin and turning mesad; 
mesoscutum distinctly rugoso-punctate, rugosities weaker in middle of each lobe, aciculated in regions of notauli and borders; scutellum and metascutellum punctate, interstices smooth and shiny; lateral carina of scutellum confined to basal 0.3 ; mesopleurum reticulate in upper half, trans-rugose above sternaulus and area below speculum, speculum largely smooth and shiny, with minute, close, indistinct punctures; prepectal carina extending to base of subtegular ridge; metapleurum with transverse wrinkles; propodeum (Fig.19) reticulate in area between basal carina and apophyses, area below apophyses trans-rugose, area basad of basal carina with fine rugosities, basal carina complete, strongly curved forward in middle, basal stumps of longitudinal carina present, apical carina represented laterally by strong crest like apophyses; spiracles oval; FWL 6.6mm; HWL - 4.7mm; FWW - 2.0mm; HWW - 1.17mm; areolet (Fig. 20) pentagonal, $5 \mathrm{x}$ as high as width of bordering veins, intercubitii slightly convergent, second intercubitus faint; nervulus slightly basad of basal vein; nervellus intercepted below middle; hind wing with one basal and seven apical hamuli.

Abdomen: First abodminal tergite $1.2 \mathrm{x}$ as long as its width at apex, $1.1 \mathrm{x}$ as long as second abdominal segment, largely smooth and shiny, with a few scattered shallow punctures towards apex; second and third tergires densely punctate; fourth and remaining tergites with shallow, indistinct punctures; length of ovipositor - $3.6 \mathrm{~mm}$; lower valve of ovipositor with distinct, series of teeth.

Colour: Black except following markings: clypeus basally in middle, mandible except at apex, tegula, subtegular ridge, base of fore wing, scutellum, metascutellum, hind margin of metanotum, apical band on first and second abdominal segments, fourth and remaining tergites broadly in middle, fore and mid coxae and fore trochanters yellow; mid trochanters, first three mid tarsal segments and fore tibia yellowish brown; flagellar segments blackish brown except fourth to eleventh flagellar segments dirty white above; ovipositor and base of first abdominal segment deep red; propodeum, a dorso-lateral patch on second abdominal tergite, hind coxa, hind trochanters and femora of all legs reddish orange; mandibular teeth, fore tarsal segments, mid tibia, fourth and fifth mid tarsal segments, hind tibia, hind tarsal segments, wing veins and ovipositor sheath brown; wings hyaline except fuscous apically.

\section{Male: Unknown.}

\section{Host: Unknown.}

\section{Biology:Unknown.}

\section{Discussion}

G. sringeriensis sp. nov. closely resembles G. apollonis Jonathan \& Gupta in having (i) rugoso-punctate face, (ii) frons black, without orbital stripes, (iii) propodeal apophyses red, and (iv) first tergite longer than second tergite. However $G$. sringeriensis sp. nov. differs from G. apollonis Jonathan and Gupta in the following features: (i) In G. singeriensis sp. nov. frons largely smooth, with fine scattered punctures, area below median ocellus weakly rugose (In G. apollonis frons largely obliquely striate in middle below median ocellus, granulose at sides); (ii) Mesoscutum distinctly rugoso-punctate, rugosities weaker in middle of each lobe in G. sringeriensis sp. nov. (In G. apollonis mesoscutum smooth or sometimes granulose); (iii) Propodeum largely reticulate, area below apophyses transrugose, area basad of basal carina with fine rugosities, extreme base smooth in G. sringeriensis sp. nov. (In G. apollonis propodeum strongly rugose, transverse below apophysis and at sides, longitudinal in middle); and (iv) In G. sringeriensis sp. nov. all abdominal tergites except third with yellow markings (In G. apollonis third to sixth abdominal tergites completely black).

G. sringeriensis sp. nov. is similar to G. rangaparensis Jonathan and Gupta in having (i) propodeum largely reticulate in middle, (ii) first abdominal tergite longer than second tergite, and (iii) metapleurum and propodeum red. However G. sringeriensis sp. nov. differs from $G$. rangaparensis Jonathan and Gupta in the following characteristics: (i) In G. sringeriensis sp. nov. face strongly rugoso-punctate (Face largely rugose in $G$. rangaparensis); (ii) In G. sringeriensis sp. nov. malar space $0.4 \mathrm{x}$ basal width of mandible (In G. rangaparensis malar space $0.75 \mathrm{x}$ basal width of mandible); and (iii) Mesoscutum distinctly rugoso-punctate, rugosities weaker in middle of each lobe in $G$. sringeriensis sp. nov. (In G. rangaparensis mesoscutum obscurely punctate, largely smooth).

\section{Goryphus townesi sp. nov.}

(Figs. 21-25)

\section{Material examined}

Holotype: Female, 10.v.2004, Valiyannur, Kannur (7521'E$11^{0} 51$ 'N), Kerala, coll. Seena Narayan (Reg. No. SK 383).

\section{Etymology}

Named after Dr. Henry Townes, the famous ichneumonologist, who contributed much to the knowledge of Ichneumonid fauna of the World.

\section{Diagnosis}

Female: Total length (excluding ovipositor) - 9.06mm. Body covered with short, fine, white hairs; hairs dense on face and propodeum; pubescence sparse on first abdominal segment.

Head: In dorsal view (Fig. 23) HL - 0.67mm and HW - 1.08mm; in front view (Fig. 22) HW - 1.08mm and HL - 1.5mm; face and clypeus subpolished, shallowly punctate, area near antennal sockets tending to be rugoso-punctate; malar space granulose, $0.8 \mathrm{x}$ basal width of mandible; mandibles with sparse punctures, apex smooth; teeth subequal; frons below ocellar area obliquely rugose, sides with minute, dense punctures, median longitudinal carina present; vertex and temple with minute, evenly distributed punctures, interstices smooth and shiny; interocellar distance 0.9x ocellocular distance, 2.0x distance between median and lateral ocelli; antenna (Fig. 21) with 31 segments; scape 1.6x as long as its width, 2.0x as long as pedicel; pedicel $0.29 \mathrm{x}$ as long as first flagellar segment; first flagellar segment 5.6x as long as 


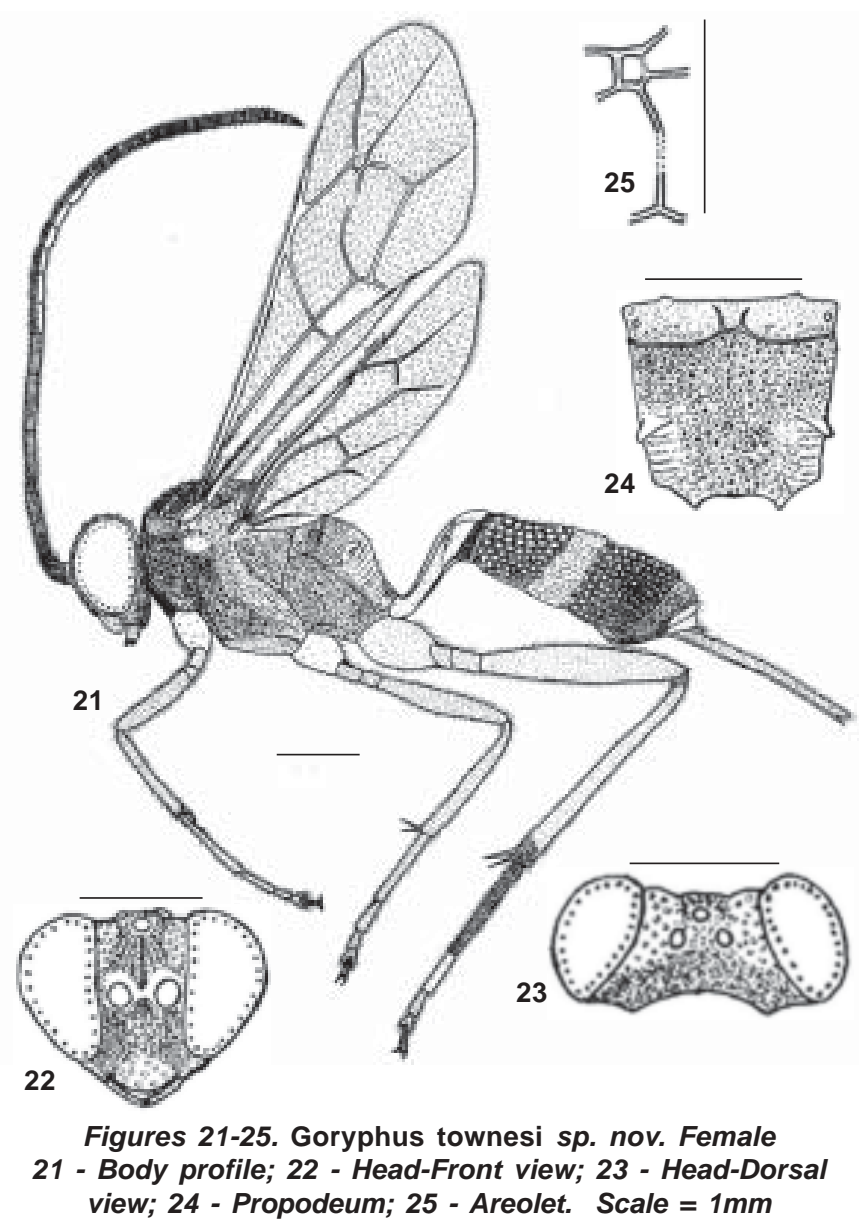

its width, 1.04x as long as second flagellar segment, 4x as long as last flagellar segment; second flagellar segment $1.04 \mathrm{x}$ as long as third flagellar segment.

Thorax: $5 \mathrm{x}$ as long as head length in dorsal view, $2.35 \mathrm{x}$ as long as width between tegulae; pronotum with oblique transverse striations in middle, upper margin strongly swollen, with longitudinal striations; epomia strong, reaching to upper margin and turning mesad; mesoscutum distinctly aciculato-punctate; scutellum and metascutellum smooth and shiny; mesopleurum reticulate, speculum smooth, with fine, scattered punctures, area below speculum rugose, area below sternaulus finely wrinkled; prepectal carina extending upto base of subtegular ridge; metapleurum reticulate, juxtacoxal carina present; propodeum (Fig. 24) reticulate, area basad of basal carina rugoso-punctate, below apophyses trans-striate, basal stumps of longitudinal carina present, basal carina complete, strongly arched forward in middle, apical carina represented by strong teeth-like apophyses, teeth blunt at apex; spiracles small and round; FWL - 6.9mm; FWW - 2.17mm; HWL - 4.6mm; HWW $1.17 \mathrm{~mm}$; areolet (Fig. 25) pentagonal, $4.5 \mathrm{x}$ as high as width of bordering veins, second intercubitus faint; nervulus slightly basad of basal vein; nervellus intercepted distinctly below middle; hind wing with one basal and seven apical hamuli.

Abdomen: First abdominal tergite $2.0 \mathrm{x}$ as long as its width at apex, $1.07 \mathrm{x}$ as long as second abdominal tergite, largely smooth and shiny, with a few punctures at apex; second to fourth tergites densely punctate, punctures on fourth weak; following tergites subpolished and mat; length of ovipositor $-2.44 \mathrm{~mm}$; lower valve of ovipositor with very weak, indistinct teeth.

Colour: Black except following markings: flagellar segments blackish-brown except fifth to eleventh flagellar segments white above; mandibles except teeth, clypeus, face with an oval mark in middle (united with clypeal mark), frons and vertex along eye margin, upper margin of pronotum, tegula, subtegular ridge, scutellum, lateral carina of scutellum, base of fore and hind wings, two elongate triangular marks on propodeum, apical band on first abdominal tergite, subapical band on second tergite, fifth to eighth tergites broadly in middle, fore and mid coxae, fore trochanters and second hind tarsal segment yellow; first abdominal tergite except apical band, fore leg except coxa, trochanters and fifth tarsal segment, mid leg except coxa and fifth tarsal segment, hind leg except extreme base and apex of tibia and tarsal segments orange; third and fourth hind tarsal segments yellowish-brown; fifth tarsal segment and claws of all legs, first hind tarsal segment, extreme base and apex of hind tibia and wing veins dark brown; wings clear hyaline.

Male: Unknown.

Host: Unknown.

Biology: Unknown.

\section{Discussion}

G. townesi sp. nov. closely resembles $G$. inferus (Szepligeti) in having (i) first abdominal tergite longer than second tergite, (ii) upper margin of pronotum strongly swollen, (iii) clear hyaline wings, (iv) aciculo-punctate mesoscutum, and (v) face yellow in the middle. However G. townesi sp. nov. differs from G. inferus (Szepligeti) in having the following features: (i) Upper margin of pronotum strongly swollen, with longitudinal striations in $G$. townesi sp. nov. (In G. inferus upper margin of pronotum with fine and sparse punctures); (ii) Prepectal carina extending upto base of subtegular ridge in G. townesi sp. nov. (In G. inferus prepectal carina extending $0.75 x$ height of mesopleurum); (iii) In G. townesi sp. nov. face with an oval mark in middle, united with clypeal mark yellow, sides black; temple completely and pronotal collar black (In $G$. inferus face with a squarish mark united with clypeal mark, face along eye margin, a broad mark on temple near base of mandible, and pronotal collar yellow); and (iv) Malar space $0.8 \mathrm{x}$ basal width of mandible in $G$. townesi sp. nov. (In $G$. inferus malar space $0.65 x$ basal width of mandible).

G. townesi sp. nov. is also similar to G. cameroni Betrem in having (i) prepectal carina extending to base of subtegular ridge, (ii) upper margin of pronotum strongly swollen, (iii) clear hyaline wings, and (iv) first abdominal tergite longer than second tergite. However G. townesi sp. nov. differs from G. cameroni Betrem in the following characteristics: (i) Malar space $0.8 \mathrm{x}$ basal width of mandible in G. townesi sp. nov. (In G. cameroni malar space $0.44 \mathrm{x}$ basal width of mandible); (ii) Third and fourth abdominal 
tergites completely black in G. townesi sp. nov. (In G. cameroni all abdominal tergites with yellow apical bands); and (iii) Vertex with minute, evenly distributed punctures, interstices smooth and shiny in G. townesi sp. nov. (In G. cameroni vertex smooth and subpolished).

\section{REFERENCES}

Ashmead, W.H. (1905). New Hymenoptera from the Philippines. Proceedings of United States National Museum 29: 107-119.

Betrem, J.G. (1941). Notes on Goryphus Holmgren, 1868 and Ancaria Cameron, 1902. Treubia 18: 45-101.

Cameron, P. (1904). Descriptions of new species of Cryptinae from the Khasi Hills, Assam. Transactions of Entomological Society, London 1904: 103-122.

Cameron, P. (1905). On the phytophagous and parasitic Hymenoptera collected by Mr. E.E. Green in Ceylon. Spolia Zeylanica 3: 67-143.

Gupta, V.K. (1987). The Ichneumonidae of the Indo-Australian Area (Hymenoptera). Memoirs of the American Entomological Institute 41(1\& 2): $1-1210$.

Holmgren, A.E. (1868). I. Hymenoptera. In: Kongliga Svenska Fregatten Eugenies Resa Omkring jorded, Zoologi, 6: 391-442.

Jonathan, J.K. and V.K. Gupta (1973). Ichneumonologia Orientalis Part III. The Goryphus-Complex (Hymenoptera: Ichneumonidae). Oriental Insects Monograph 3: 1-203.

Sathe, T.V. and R.K. Dawale (1997). Two new species of the genus Goryphus Holmgren (Hymenoptera: Ichneumonidae) from India. Hexapoda 9(1\&2): 57-64.

Tosquinet, J. (1903). Ichneumonides nouveaux (Travail Posthume). Memoires de la Societe Entomologique de Belgique 10: 1-403.

Townes, H.K. (1969). The genera of Ichneumonidae. Part I. Memoirs of the American Entomological Institute 11: 1-300.

Wahl, D.B. (1999). Classification and Systematics of the Ichneumonidae (Hymenoptera). http://iris.biosci.ohiostate.edu/catalogs/ichneumonids. Yu, D.S. (2002). Taxapad 2002-Interactive Catalogue of Ichneumonidae 1998. www.taxapad.com/ich1998.html.

\section{ACKNOWLeDGements}

The first author (KS) is grateful to the University Grants Commission, New Delhi for the award of Senior Research Fellowship. We also thank the authorities of the University of Calicut for the facilities provided.

\section{NOTE ON THE TYPE MATERIAL OF OPHELOSIa MACULATA SURESHAN AND NARENDRAN (HYMENOPTERA: CHALCIDOIDEA: PTEROMALIDAE)}

\section{P.M. Sureshan}

Estuarine Biological Station, Zoological Survey of India, Gopalpur-on-sea, Orissa 761002, India

Email: samanyu2003@yahoo.com

Sureshan and Narendran (2005) described a species of Ophelosia Riley, O. maculata in the subfamily Eunotinae of Pteromalidae. The description was based on specimens reared from unidentified coccids on Hibiscus roasasinensis from Pune, Maharashtra, India. The authors had not mentioned the depository of the primary type material of the species in the description, an error, according to Article 16.4.2 of the latest International Code of Zoological Nomenclature (ICZN, 1999) the scientific name of which is considered unavailable (Dr. John. S. Noyes, Natural History Museum, London, in litt., 4 October 2005). In order to make the name Ophelosia maculata Sureshan \& Narendran available for future work, the relevant details of the type material are published herein.

\section{Name of the taxa:}

Ophelosia maculata Sureshan \& Narendran, 2005.

\section{Type material:}

Holotype: Female, 20-23. iii.2004, Dehuroad, Pune, Maharashtra, India, ex. Coccids (unidentified) on Hibiscus rosasinensis (Reg. No. ZSI/EBS/I 3812).

Paratype: Male, data same as that of holotype (Reg.No.ZSI/ EBS/I 3813) (Currently housed in the collections of Zoological Survey of India, Estuarine Biological Station, Gopalpur-on-sea, Ganjam, Orissa, India but eventually will be deposited in the National Zoological Collections, Zoological Survey of India, Kolkata (NZSI).

\section{REFERENCE}

Sureshan, P.M. and T.C. Narendran (2005). Description of a new species of Ophelisia Riley with synonymic and taxonomic notes on Indian Eunotinae (Hymenoptera: Chalcidoidea: Pteromalidae). Zoos' Print Journal 20(5): 1854-1855. 